$$
\text { DOE|DC| }
$$

$\mathrm{DOE} / \mathrm{PC} / 90285--\mathrm{T} 3$

DE92 010000

\title{
SYNERGISTIC CAPTURE MECHANISMS FOR ALKALI AND SULFUR SPECIES FROM COMBUSTION
}

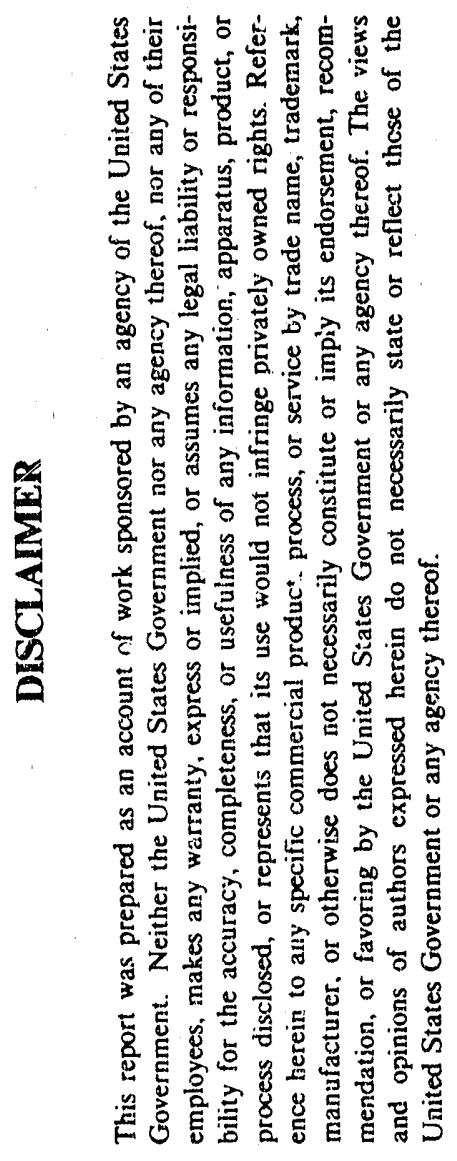

\author{
Quarterly Report No. 2 \\ for the period December 1990 - February 1991 \\ DOE Grant Number DE-FG22-90PC90285 \\ Prepared by \\ T.W. Peterson, F.Shadman, J.O.L. Wendt and Edward Olsen \\ Department of Chemical Engineering, \\ University of Arizona, \\ Tucson, AZ 85721
}

Submitted to

Felixa Eskey, Pittsburgh Energy Technology Center,

U.S. Department of Energy,

P.O.Box 10940

Pittsburgh, PA 15236-0940

January 10, 1992. 


\section{Summary}

An aerosol reactor system has been designed and constructed for the systematic study of the mechanisms governing the possible synergistic capture of sulfur oxide and alkalis with aluminosilicates and lime $(\mathrm{CaO})$. Actual particle dynamics found in coal combustor systems can be simulated, mass balances can be closed, and the system conditions are well controlled. The collection of hot reactive aerosol flows is performed utilizing an isokinetic probe.

\section{Aerosol Reactor Design}

\section{Initial Considerations}

The initial reactor design was based on work done by Quann, Neville, Janghorbani, Mims, and Sarofim (1982) with their laminar flow combustor furnace, collection probe and coal feeding system. A schematic diagram of the aerosol reactor is presented in Figure 1. A solution of sodium chloride is atomized at $0.5 \mathrm{ml} / \mathrm{min}$ and transported with nitrogen through a quartz tube heated with an electric furnace to $800^{\circ} \mathrm{C}$. The water is vaporized, leaving suspended sodium chloride particles which are also eventually vaporized. The initial concentration profile is assumed to be uniform radially. The mixture is collected with an isokinetic probe which is inserted axially along the tube centerline from the exit end. The coal feeder design by Quann et al. was used as a basis for the construction of a steady-state sorbent feeder. Kaolinite feedrates varied from 0.023 to $0.6 \mathrm{~g} / \mathrm{min}$ with nitrogen carrier flowrates of $2-51 / \mathrm{min}$.

The reactor size was designed to provide residence times simulating those in a large-scale combustor furnace (approximately 3 seconds) while minimizing the deposition losses to the reactor walls and minimizing the total gas flowrate. Impaction of sodium chloride aerosols to the walls from diffusion is assumed to result in complete loss of impacted particles due to sticking. The concentration of sodium is assumed to be uniform radially at the reactor inlet. Ideally, as the mixture traverses the length of the tube, the sodium concentration is depleted near the wall while remaining nearly unchanged at the centerline. The optimum tube diameter and gas flow rate was determined to satisfy thir: condition for an average residence time of 3 seconds and tube length of $100 \mathrm{~cm}$.

\section{Design Modeling}

The governing equation describing the sodium concentration, $\mathrm{C}(\mathrm{z}, \mathrm{r})$, as a function of length $(z)$ from reactor inlet, and radial distance from the tube centerline $(r)$ is given by:

$$
v_{z} \frac{\partial C_{a}}{\partial z}=\frac{D}{r} \frac{\partial}{\partial r}\left\lfloor r \frac{\partial C_{a}}{\partial r}\right\rfloor
$$




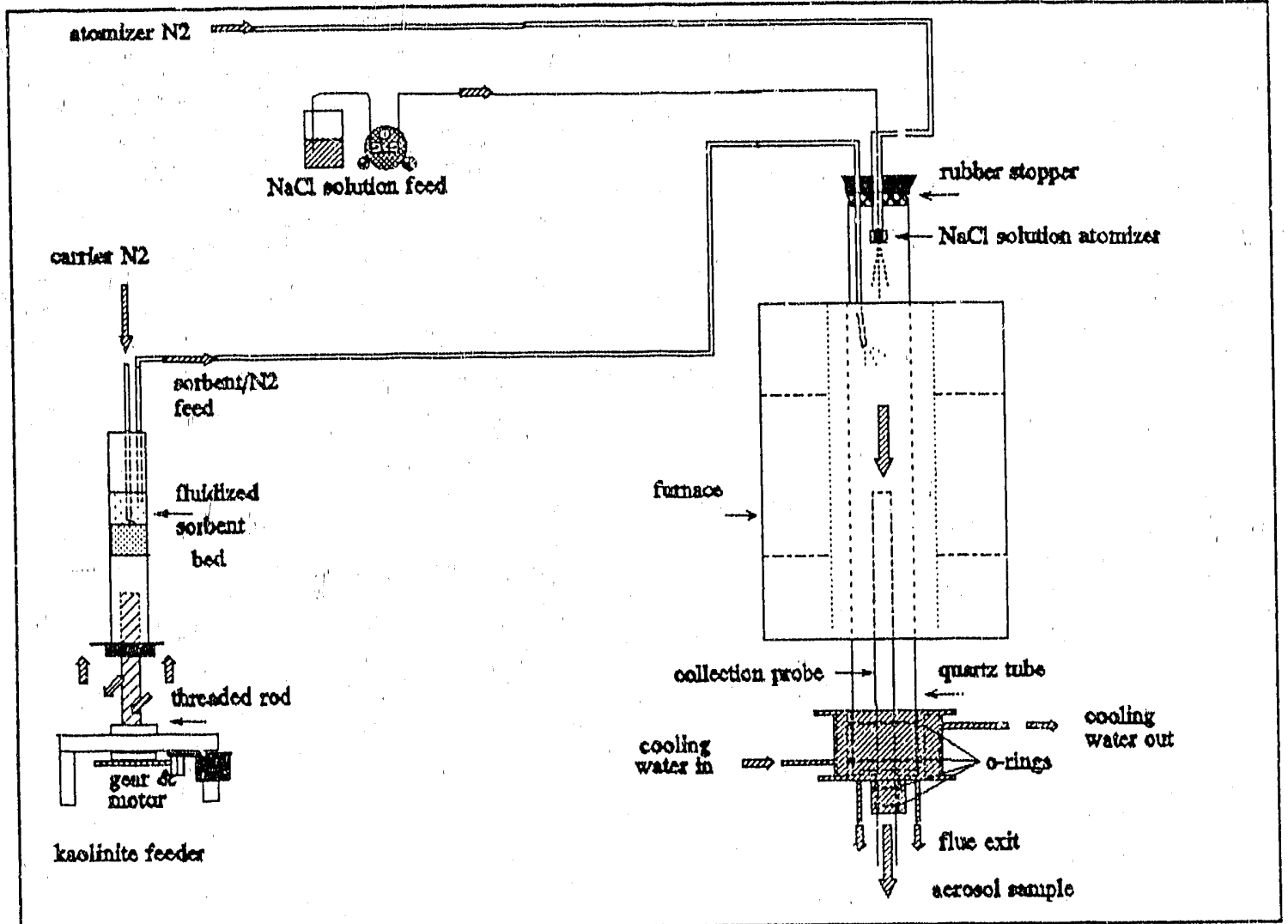

Figure 3: Ferosol Reactor system

The boundary conditions are:

$$
\begin{array}{lr}
\mathrm{C}_{\mathrm{a}}(0, \mathrm{r})=\mathrm{C}_{\mathrm{a} 0} & \text { at } \mathrm{z}=0, \text { all } \mathrm{r} \text { (tube inlet) } \\
\mathrm{C}_{\mathrm{a}}(\mathrm{z}, \mathrm{R})=0 & \text { all } \mathrm{z}, \mathrm{r}=\mathrm{R} \text { at the tube wall } \\
\underline{\partial \mathrm{C}_{\mathrm{a}}(\mathrm{z}, \mathrm{r})}=0 & \text { all } \mathrm{z}, \mathrm{r}=0 \text { at the centerline }
\end{array}
$$

The distance between the centerline and the wall is assumed large enough so that the sodium species does not "fee!" the presence of the wall and is travelling with a velocity equal to the velocity at the centerline. If the flow follows laminar theory (Reynolds No. $(\mathrm{Re})=127$ for 8 SLPM), the velocity at the centerline is just twice the average velocity of the total flow. The gas velocity, $v_{z}$, then was approximated by the maximum velocity, $\mathrm{V}$ and the solution to the differential equation was found to be in the form of Bessel's Equations : 


$$
C_{a}(z, r)=\sum_{n=1}^{\infty} A_{n} \exp \left(-\mu_{2}^{2} z^{*}\right) J_{0}\left(\frac{\mu_{n}}{B^{1 / 2}} r^{*}\right)
$$

where $B=D L / R^{2} V$

$$
\begin{aligned}
& \mathrm{R}=\text { tube radius } \\
& \mathrm{L}=\text { tube length } \\
& \mathrm{V}=\text { average velocity } \\
& \mathrm{D}=\text { particle diffusivity } \\
& \mathrm{z}^{*}=\mathrm{z} / \mathrm{L}, \text { nondimensionalized length } \\
& \mathrm{r}^{*}=\mathrm{r} / \mathrm{R}, \text { nondimensionalized radius } \\
& \mathrm{A}_{\mathrm{n}}=\frac{2}{\mathrm{j}_{0, \mathrm{n}} \mathrm{J}_{1}\left(\mathrm{j}_{0, \mathrm{n}}\right)} \\
& \mathrm{j}_{0, \mathrm{n}}=\mu_{\mathrm{n}} / \mathrm{D}^{1 / 2}, \text { Bessel's roots }
\end{aligned}
$$

The Bessel equations were solved using polynomial approximations (Abramowitz and Stegun, 1965) for Bessel's roots. The particle diffusivity is dependent upon particle size. The concentration profile as a function of length and radius was calculated for different particle diameters $(0.001-100 \mu \mathrm{m})$, tube diameters, and gas flowrates at $800{ }^{\circ} \mathrm{C}$. A tube diameter of approximately $5 \mathrm{~cm}$ was determined to be the optimum with a flowrate of 11 slpm.

\section{Reactor Tube}

The actual tube size, based on availability, has a diameter of $4.05 \mathrm{~cm}$, and a total gas flow of 8 SLPM yields an average velocity of $37 \mathrm{~cm} / \mathrm{s}$ at $800{ }^{\circ} \mathrm{C}$. The Bessel's equations were calculated under these conditions for a tube $100 \mathrm{~cm}$ long and the nondimensionalized concentration profiles for three different particle sizes can be seen in Figures 2-4. These results show that nearly all particles with diameters greater than $0.01 \mu \mathrm{m}$ are recovered at the centerline $100 \mathrm{~cm}$ downstream of the tube inlet. Diffusional losses become a factor only for particle diameters less than $0.001 \mu \mathrm{m}$.

Quartz was selected as the reactor tube material for its stability in a high temperature environment, low thermal conductivity and minimal thermal expansion properties. Mullite, another option, is considerably more expensive and may contain potassium which could contaminate the reaction zone. The ends of the reactor tube were closed with water-cooled stainless steel sleeves sealed with Viton O-rings. The sleeves are cooled to prevent expansion. The O-rings are capable of handling temperatures up to $200{ }^{\circ} \mathrm{C}$ before breakdown. By extending the ends of the quartz tube outside of the 
furnace heating zone, the tube wall at the seals is kept below this limiting temperature. The collection probe is inserted through the sleeve at the exit and also sealed with Viton O-rings. The temperature at the front end of the quartz tube was found to be low enough to replace the sleeve at the inlet with a simple rubber stopper. Implementing a rubber stopper enables changes in the feed configuration to be performed easily. The atomizer is inserted just before the furnace to prevent the solution from vaporizing inside the atomizer. The kaolinite injection position can be adjusted axially.

\section{Reactor Tube Heating}

The reactor tube is heated with three sections of insulated, cylindrical, electric heating elements with ID's of three inches. The furnace is capable of generating temperatures up to $1150{ }^{\circ} \mathrm{C}$. The three sections are currently connected to one variable power source, however, detailed control over the shape of the temperature profile can be realized by the addition of two mc re variacs. Attainment of a constant temperature profile in the reactor would allow experiments to be conducted within a well-defined temperature "window". Two of the sections are each six inches in length and the third is 12 " for a total furnace length of $24 "$.

\section{Alkali Feed System}

The alkali is introduced to the reactor in solution, atomized and vaporized. A variablespeed Masterflex peristaltic pump transports the alkali solution to the atomizer. The alkali mass rate can be controlled by either changing the pump speed or changing the concentration of the solution. The amount of sodium that vaporizes depends upon the sodium partial pressure, $\mathrm{P}$ and the saturation vapor pressure, $\mathrm{P}^{*}$, at the system temperature. The saturation vapor pressure is determined from Antoine's equation (Smith and Van Ness, 1975):

$$
\ln P^{*}=A-\frac{B}{T+C}
$$

Where $\mathrm{A}, \mathrm{B}, \mathrm{C}$ are constants specific for the component of interest. If the saturation ratio $\mathrm{P} / \mathrm{P}^{*}$ is initially zero, sodium will continue to vaporize until the ratio approaches unity or the unvolatized form is depleted (Hinds, 1982). An alternative approach used by Uberoi, Punjak and Shadman (1990) for feeding the alkali is to vaporize solid alkali in a heated crucible and transport it with a carrier gas. The concentration of the alkali is controlled by the temperature of the crucible and the flowrate of the carrier gas. Atomization of an alkali solution, however, provides a more direct means of controling the alkali concentration. 


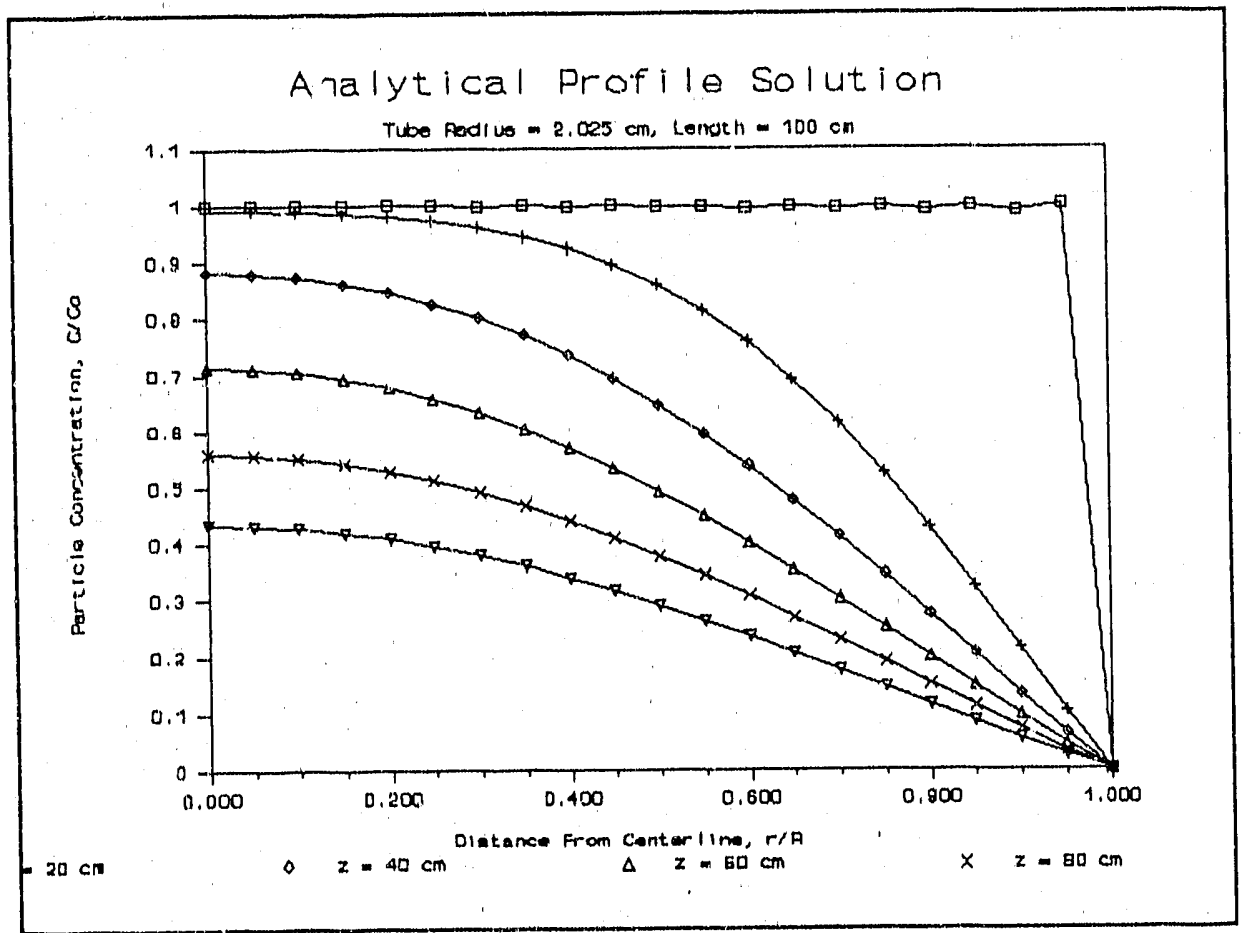

Figure 4: Gas Species Profile

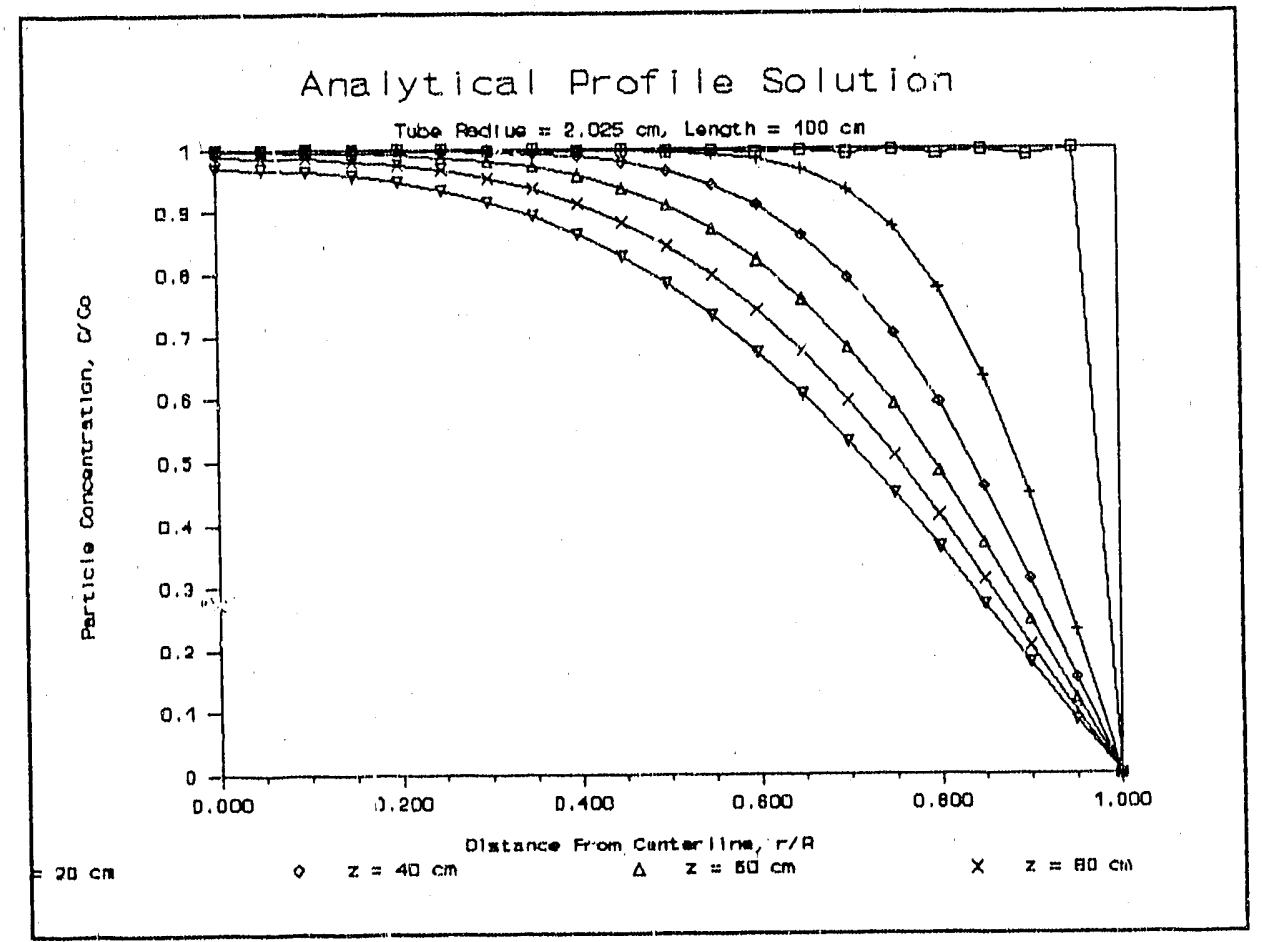

Figure 5: 0.001 $\mu \mathrm{m}$ Particle Profile: 


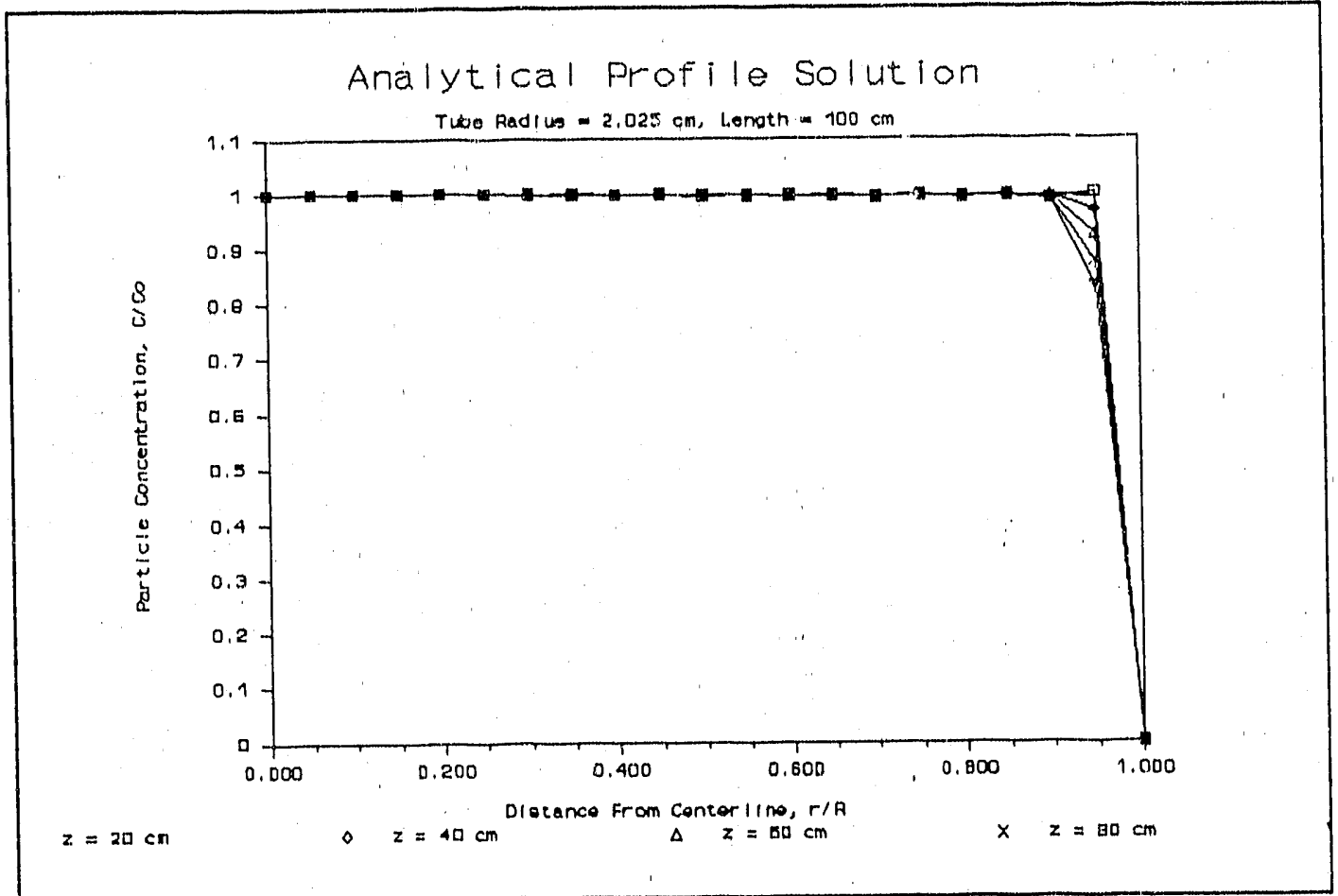

Figure 6: 0.01 $\mu \mathrm{m}$ Particle Profile

\section{Sorbent Feed System}

A sorbent feeder has been built using the principles presented by Quann, et al., for their coal feed system. The sorbent is placed in the bottom of an acrylic cylinder. Nitrogen is blown into the sorbent bed through several small tubes, a fluidiziad layer is formed and sorbent particles are entrained into an outlet line, and transported to the reactor. The bed is raised at a constant rate towards the nitrogen inlet and outlet such that a constant fluidized bed level is established after approximately 15 minutes. The concentration of the sorbent can be changed by varying the nitrogen flowrate or the velocity of the bed ascension. The stickiness of kaolinite presents fluidization and entrainment problems and the sorbent must be carefully dried before feeding... Screw feeder techniques were also considered but were found to be highly unrecommended for generation of steady, low feedrates for sticky powders such as coal and kaolinite.

\section{Particle Collection Probe}

The collection probe is designed to quickly quench and dilute the sample with nitrogen to promote scdium vapor nucleation and prevent vapor/aerosol deposition inside the probe tip and sample line. The probe tip design is presented in Figure 5. Cooling the sample stream will sharply decrease the sodium saturation vapor pressure and increase 
the saturation ratio $\mathrm{P} / \mathrm{P}^{*}$, forcing nucleation. Dilution minimizes particle interactions leading to coagulation. When water vapor is present in the sample, sufficient dilution is also necessary to prevent supersaturation and subsequent nucleation and condensation of water at room temperatures. Nitrogen is added to the sample mixture radially through a 12 " section of $1 / 4$ " OD porous stainless steel tubing. The sample and dilution/quench $\mathrm{N}_{2}$ is pulled through the sample line with a vacuum pump from the DMPS. Two channels allow water flow through an external water jacket to provide cooling to the probe. Only one shell is used for the jacket as opposed to a larger, double-shelled configuration to reduce streamline deformation in the reactor flow.

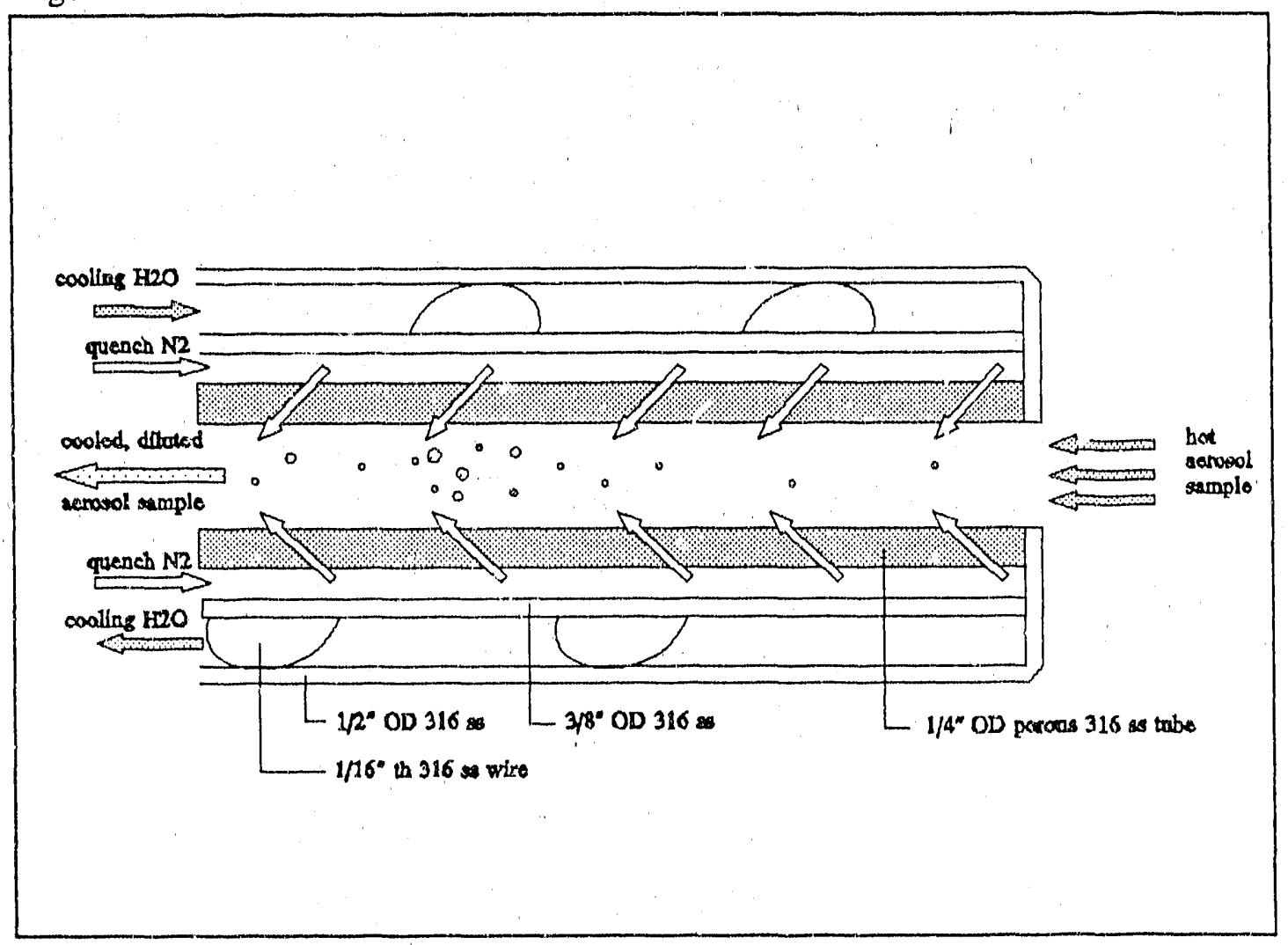

Figure 5: Collection Probe Design

\section{Particle Size Measurement System}

The polydisperse aerosol concentration, generated by the nucleation, condensation and coagulation of sodium, is measured using a DMPS system. The polydisperse particles are segregated with a TSI Electrostatic Classifier (Model 3071) into channels which correspond to the different particle mobilities in an electric field, and consequently, irto channels of various particle size ranges. The number concentration of the particles in 
each of the size ranges is measured with a TSI Condensation Nuclei Counter (Miodel 3025). A particle size distribution is then generated with DMPS software.

\section{Preliminary Experimental Results}

Preliminary experiments were conducted using nitrogen as a carrier gas, the alkali, sodium, as sodium chloride at $80{ }^{\circ} \mathrm{C}$. Sodium particle size distributions, shown in Figures 6-11, were measured using a DMPS which consists of a TSI Electrostatic Classifier and Condensation Particle Counter. High number concentrations of ultrafine sodium particles with diameters in the 0.01-0.4 micron range were generated in the sample probe. Initial results indicate large deposition losses $(93 \%)$ occur in the system. Kinetic data suggests that in the presence of water vapor, $\mathrm{NaOH}_{(v)}$ and $\mathrm{HCl}_{(v)}$ are in equilibrium with $\mathrm{NaCl}_{(v)}$. Litmus tests indicate that $\mathrm{NaOH}$ exists on the reactor walls after sodium runs.

Several preliminary experiments have been performed in an attempt to characterize the system performance and the deposition losses in the reactor and collection probe. Particle size distributions obtained from the DMPS can be seen in Figures 6-11. Flowmeters were calibrated and a total mass balance of nitrogen on the system was executed to assure that no leaks exist from the outlet sleeve seals, the sorbent feeder and the tubing connections. The DMPS system flows were calibrated to fit the reactor system specifications. Particle size distributions were measured at the exit end of the furnace at $800{ }^{\circ} \mathrm{C}$ using only nitrogen as a particle background check. The water was then atomized and introduced into the reactor, additional concentration measurements were taken, and the procedure repeated with sodium added to the water. Blank nitrogen runs, as seen in Figures 6 and 7, exhibit no appreciable background particles, as expected. When atomized water was added and vaporized in the reactor, particle number concentrations (Figures 8 and 9) were on the order of ten per standard $\mathrm{cm}^{3}$ and some moisture could be seen in the sample line leading to the DMPS. Suspicions of a water leak in the collection probe were abated when the dilution ratio was found to be too low. The dilution ratio was raised to $11: 1$, no presence of water in the sample line was detected and the particle number concentrations were considerably lower. Sodium was then added to the water and the solution vaporized in the reactor at $800{ }^{\circ} \mathrm{C}$. The sodium mass feedrate was $0.0016 \mathrm{~g} / \mathrm{min}$ with an initial concentration of $2.0 \times 10^{-7} \mathrm{~g} / \mathrm{std} \mathrm{cm}^{3}(300$ $\mathrm{ppm})$. Particle number concentrations were measured before plugging in the atomizer forced a shutdown. The atomizer was cleaned and positioned further from the furnace entrance to prevent premature vaporization of the water. The run was repeated and simila: data was taken and is presented in Figures 10 and 11. The total sodium volume concentration of the undiluted mixture was $6.303 \mu \mathrm{m}^{3} / \mathrm{std} \mathrm{cm}^{3}$. This yields a mass concentration of $1.4 \times 10^{-8} \mathrm{~g} / \mathrm{std}^{3} \mathrm{~cm}^{3}$, only a $7 \%$ recovery of the sodium at the inlet. The analytical solution predicts that nearly all of the $0.001 \mu \mathrm{m}$ particles should remain at the 
centerlire, $61 \mathrm{~cm}$ downstream of the furnace inlet. This discrepency must be resolved.

Instantaneous expansion into the reactor tube from the atomizer orifice forces the spray to spread quickly. Impaction of the solution spray was observed on the reactor wall just before the furnace inlet. Settling of the larger water droplets was also seen further downstream. The addition of sheath nitrogen around the atomizer will reduce the spray expansion. A smaller orifice in the atomizer head can 


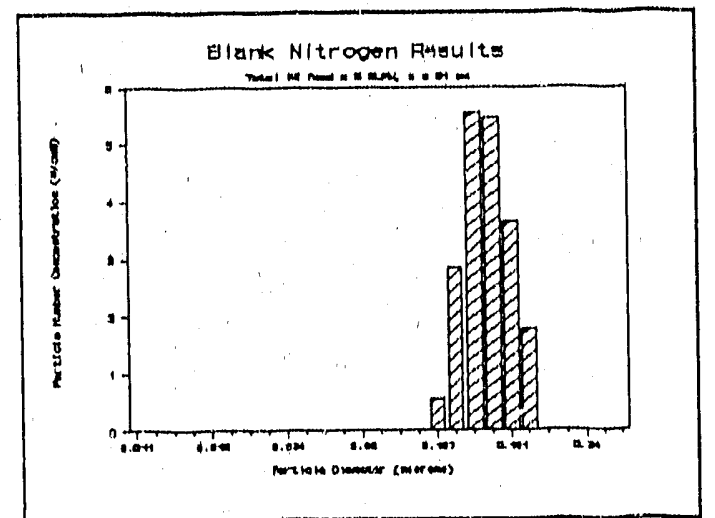

Figure 6

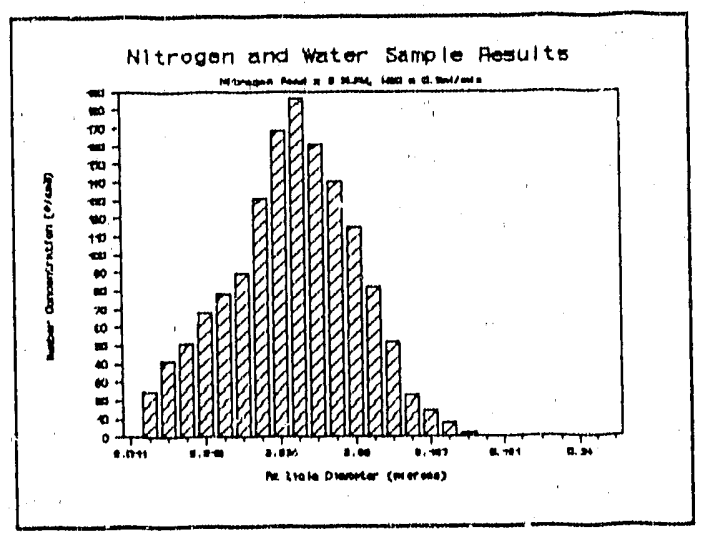

Figure 8

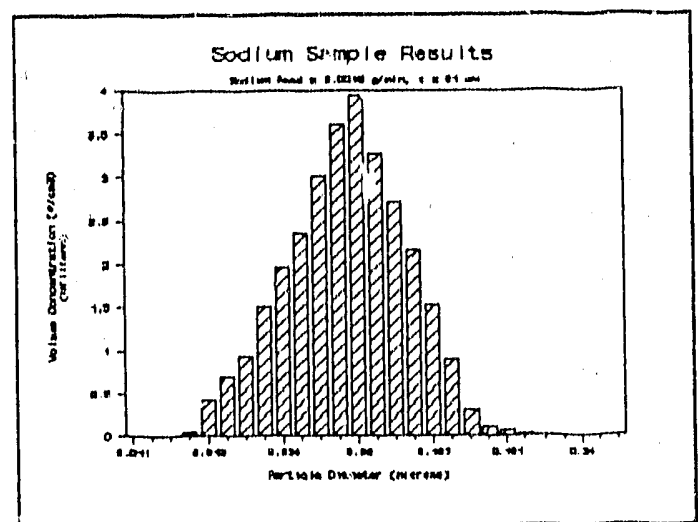

Figure 10

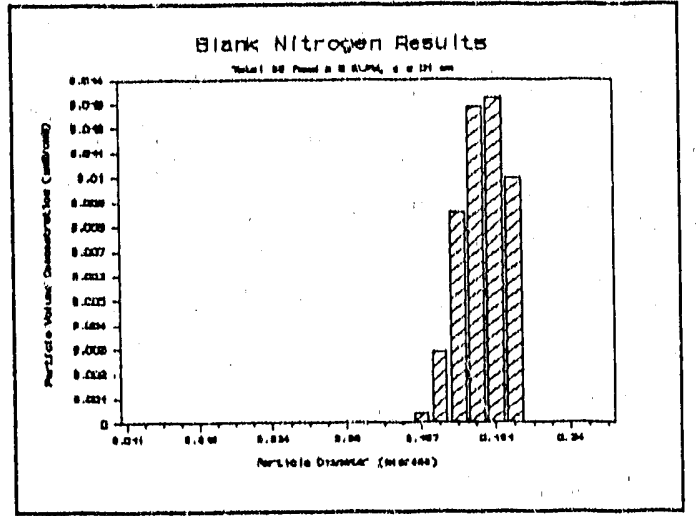

Figure 7

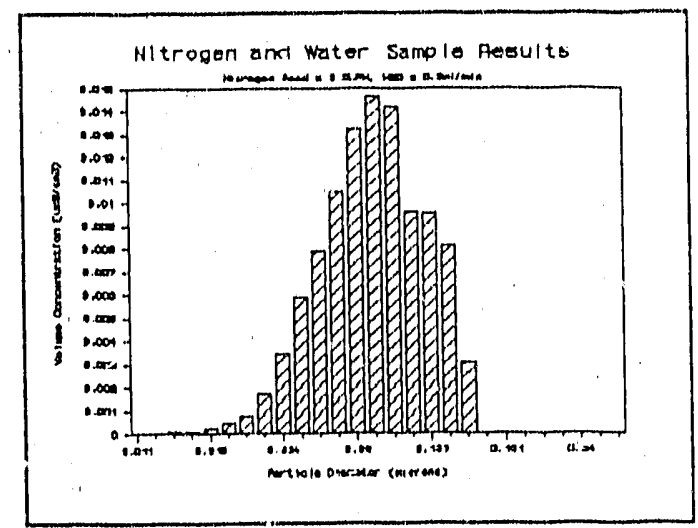

Fignre 9

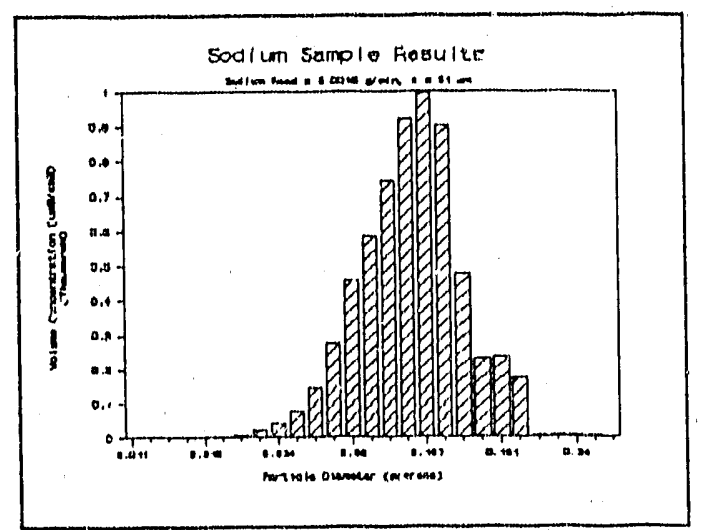

Figure 11 
generate smaller water droplets that are less likely to settle.

Kinetic data presented by S. Srinivasachar, J.J. Helbe, D.O. Ham and G. Donlazetis (1990) suggests that in the presence of water vapor, sodium chloride will react with the water to form $\mathrm{NaOH}$ and $\mathrm{HCl}$. In equilibrium at $800{ }^{\circ} \mathrm{C}$, approximately $40 \%$ of the reactor walls show a slight presence of the sodium will exist as $\mathrm{NaOH}$. The sodium chloride will be continuously depleted if the $\mathrm{NaOH}$ in the vapor phase reacts with the walls or nucleates and condenses. Litmus tests show a small presence of a base on the reactor wall. A litmus test was taken of a section of quartz known to have reacted with $\mathrm{NaOH}$ and similar results were provided. To prevent the production of sodium hydroxide, the water must be removed. A diffusion dryer will be added to remove the water vapor from the flow before it enters the furnace zone.

\section{Future Work}

Future work will involve completing the characterization of the aerosol reactor. Sulfur dioxide will be added to the system to investigate its effects on the sodium concentration. The alkali capture mechanisms will then be examined with the addition of kanlinite and kaolinite impregnated with lime $(\mathrm{CaO})$. Work by Sieinberg and Schofield (1990) suggests that formation of $\mathrm{NaSO}_{2}, \mathrm{Na}_{2} \mathrm{SO}_{4}$ and other sodium-sulfur products will occur with the addition of sulfur to a sodium environment. When the sodium losses by deposition and side reactions can be characterized, sodium capture with kaolinite can be systematically studied. Kaolinite will be impregr ated with lime $(\mathrm{CaO})$, a known scrubber for $\mathrm{SO}_{2}$. The simultaneous capture of sulfur and sodium will then be explored and an attempt to clarify the reaction mechanisms will be made. 
Bibliography

Quann, R.J., Neville, M., Mims, C.A., and Sarofinn, A.I., "Mineral Matter and TraceElement Vaporization in a Laboratory-Pulverized Coal Combustion System", Environ. Sci. Technol., 16, 776-781 (1982).

Abramowitz, M., and Stegun, I. A., Handbook of Mathematical Functions, Dover Publications, New York (1965).

Smith, J. M., and Van Ness, H. C., Introduction to Chemical Engineering Dynamics, Third Edition, McGraw Hill Book Company (1975).

Hinds, W. C., Aerosol Technology, John Wiley \& Sons, Inc. (1982).

Uberoi, M., Funjak, W.A., and Shadman, F., "The Kinetics and Mechanism of Alkali Removal From Flue Gases By Solid Sorbents", Prog. Energy Combust. Sci., 16, 205-211 (1990).

Srinivasachar, S., Helbe, J.J., Ham, D.O., and Domazetis, G., "A Kinetic Description of Vapcr Phase Alkali Transformations in Combustion Systems", Prog. Combust. Sci., 16, 303-309 (1990).

Steinberg M., and Schofield, K., "The Chemistry of Sodium with Sulfur in Flames", Prog. Energy Combust. Sci., 16, 311-317 (1990). 

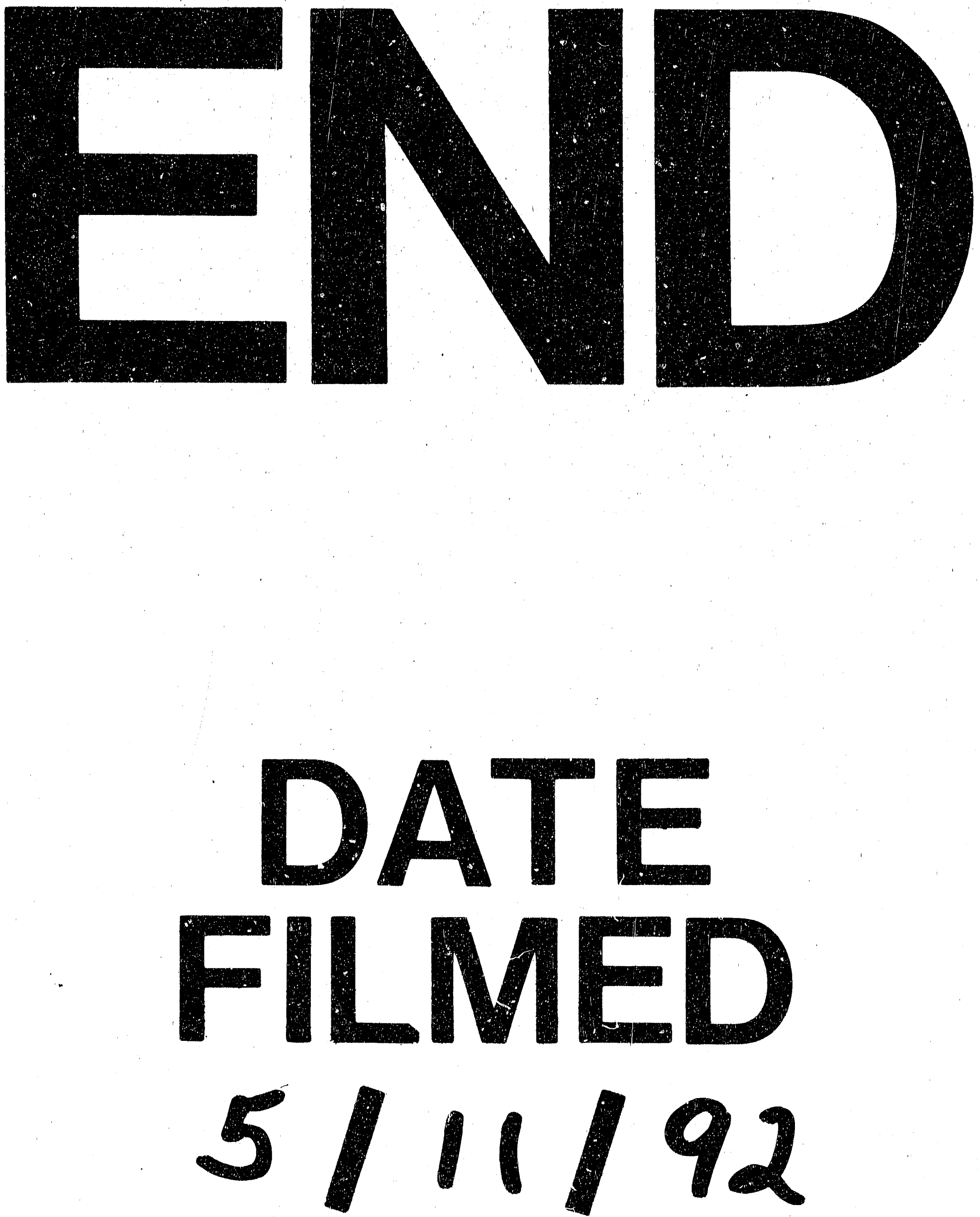

f 
